\title{
Development of a Fiber Optical Occlusion Based Non-Contact Automatic Tool Setter for a Micro Milling Machine
}

\author{
Xinyu Liu, Weihang Zhu \\ Department of Industrial Engineering \\ Lamar University \\ Beaumont, TX 77710
}

\begin{abstract}
The objective of this research is to create a low cost non-contact automated tool setter to reduce the overall tool setup time for a micro-milling machine. The accuracy of tool setting has a direct impact on the outcome of machining. The research focused on addressing the tool setting in the Z-axis (spindle axis), which is needed for each tool change and accounts for the majority of the total tool setting time. A fiber optic FS-V30M sensor from Keyence that is equipped with a light emitting element and receiving sensor was used. The sensor detects the position of the micro-tool by measuring the light intensity change as the tool crosses the emitted light beam. A bracket was designed and manufactured to mount on the workpiece pallet to hold the fiber optic cable. A novel search/detection algorithm was developed and implemented in the CNC machine controller. Controlled experiments were conducted to test the performance of the tool setter. The system achieved $0.6 \mu \mathrm{m}$ repeatability and $2 \mu \mathrm{m}$ accuracy across different sizes of micro-tools. The execution of each tool setting takes about 10 seconds, which is $80 \%$ 90\% reduction from the manual tool setting.
\end{abstract}

\section{INTRODUCTION}

In response to the rising demands of miniature components, a tremendous amount of research and development work has been centered on developing innovative manufacturing equipment and processes for cost-effective manufacture of small precision parts, especially those involving complex 3D geometry. Micro-mechanical machining with miniature machine tool (mMT) is such an emerging technology, which offers many advantages over conventional machines including significantly reduced cost, space, and energy consumption [1] [2] [3] [4]. Tool setting measures the cutting tool length which must be completed before any machining tasks can be executed. The accuracy of tool 
setting has a direct impact on the outcome of machining. Tool setting for conventional machines can be based on either contact or non-contact sensors. The contact sensor-based precise tool setting or calibration may be based on a touch probe and an electronic tool setter [5]. The non-contact automatic tool setter for conventional machine tools are commercially available from several vendors, such as Blum Micro Compact [6], and Renishaw NC4 [7]. But none of these commercial systems is small enough or ready to be adopted in the micro-machine tools. K. Popov et al. [8] developed a new tool-workpiece setup technology based on the detection of abrupt voltage variations as the tool touched the workpiece by forming a closed electric circuit between the spindle and the workpiece. The idea stemmed from the tool-workpiece voltage monitoring system developed for detecting a tool breakage during micro-milling and micro-drilling [9].

Due to the small size of the tool used in the micro-machining operations, tool setting is one of the most challenging and time-consuming tasks. The diameter of a typical micro-endmill are in the range of 50 500 $\mu \mathrm{m}$, which can be barely seen with naked eyes. The current practice is to bring the micro-tool to gradually approach the workpiece surface with the hand-wheel and monitor the process through a magnifying lens. Once the micro-tool touches the surface, the operator will set the current machine location as zero location in $\mathrm{Z}$ axis (along the tool axis). This manual process is not only tedious but also time-consuming. For a typical machining part with features on both sides, a minimum two fixture setups are needed to complete manufacturing. For each fixture, the machining sequence normally consists of three stages: roughing, semi-finishing, and finishing. Each stage involves at least one tool change and one tool setting. Therefore, it is common to have a total of 6 tool changing/setting for each part. Assuming each manual tool setting takes 3 minutes, the total tool changing/setting time can be up to 20 minutes. This time accounts for roughly $20-40 \%$ of the total machining time. Furthermore, fragile micro-tools are susceptible to breakage with the manual tool setting due to the contact between the tool and the workpiece. A non-contact automatic tool setting system is desirable for improving the tool setting process.

The objective of this research is to develop a non-contact automatic tool setter for micro-milling machine so that tool setup time can be significantly reduced. The rest of the paper is organized as follows. Section 2 presents the system design and operating principle. Section 3 discusses the tool tip detection algorithm. The experimentation results of system repeatability and accuracy is presented in Section 4, followed by the conclusions in Section 5 . 


\section{SYSTEM DESIGN AND OPERATING PRINCIPLE}

The goal of tool setting is to establish the workpiece coordinate origin for tools with different lengths so that for any given tool, the zero coordinate of $\mathrm{Z}$ axis corresponds to the location where the tool tip touches the reference surface on the workpiece. A tool setter is a device that is designed to facilitate the tool setting process. It is fixed on the machine, and contains a sensing unit to detect the location of the tool tip. The sensing unit replaces the reference surface to register the location of the tool so that the contact between the tool tip and the reference surface can be avoided during the tool setting process. This is especially beneficial in micro-machining since the micro-tools are usually tiny and very fragile.

In this work, the tool setter was designed and implemented on a Microlution S310 3-axis horizontal micro-milling machine. The machine has a working volume of 2.5 by 2.5 by 2.5 inches driven by linear motors with the encoder resolution of $20 \mathrm{~nm}$ in each axis. The main component of the tool setter is a fiber optical thrubeam type sensor Keyence FS-V30M. The sensor costs less than $\$ 200$, which is about 3\% 5\% of a commercial tool setter's cost. It also has a very small size and high spatial resolution and sensitivity. All are desirable features for a confined space of a micro-milling machine. The sensor emits a light beam from its light-emitting element, and the receiver side of the sensor converts the light intensity received to an electric voltage proportionally. This sensor will detect an object (micro-tool) when it crosses the optical axis between the transmitter and the receiver since the light intensity will have a measurable decrease. The smallest detectable object is $5 \mu \mathrm{m}$, which is perfect for detecting the micro-tools. The transmitter and receiver of the sensor are $1 \mathrm{~mm}$ in diameter connected by a long cable to the signal conditioning module and were fixed on the mounting bracket using set screws. The through holes on both sides of the mounting bracket (shown in Figure 1) were drilled in the same drilling cycle to ensure the receiver and the transmitter is co-axial. The mounting bracket was fixed on a designated base plate of workpiece pallet. Figure 2 shows the system configuration of the fiber optical occlusion tool setter in the machine coordinate system.

Figure 1: Mounting bracket to hold transmitter and receiver of fiber optical sensor

Figure 2: System configuration of the fiber optical occlusion tool setter 
The analog measurement of the light intensity in voltage was gathered by the machine controller (DeltaTau Turbo PMAC2) through an A/D converter. The collected data were then used to trigger tool tip detection.

For a micro-machining job, the tool setting process using the non-contact automatic tool setter involves the following two steps.

- First, a probe (can be an endmill with a relatively large diameter, e.g., $500 \mu \mathrm{m}$ ) is used to measure the displacement $(d)$ between the edge of the light beam and the reference surface of the workpiece in the $\mathrm{Z}$ direction. Two encoder readings are recorded when the probe was on the edge of the light beam $(z l)$ and when the probe touched the reference surface $(z 2)$, respectively. The difference between $z 2$ and $z 1$ is the displacement $(d)$. This displacement $(d)$ is fixed for a given workpiece and was registered in the machine controller once the measurement was done. This fixed displacement (d) will later be used to offset the tool length for the subsequent tool changes under the same fixture setup.

- Second, the probe is taken out from the spindle and a new tool is installed. The new tool tip will be brought to the edge of the light beam and the corresponding encoder reading of $\mathrm{Z}$ axis $(z 3)$ will be recorded. Finally, the proper $\mathrm{Z}$ axis zero for the tool (where the tool tip aligns with the reference surface) will be established by offsetting the distance $d$ from $z 3$. It is evident that the most crucial step in tool setting is to detect the tool tip location using the fiber optical sensor so that $\mathrm{z} 1$ and $\mathrm{z} 3 \mathrm{can}$ be measured.

The tool tip detection procedure and algorithms will be discussed in detail in the next section.

\section{TOOL TIP DETECTION PROCEDURE AND ALGORITHMS}

\subsection{WHITE NOISE ANALYSIS OF THE SENSOR SIGNAL}

In order to set the sensor signal threshold for tool tip detection, it is necessary to know the magnitude of the signal noise and the resolution of the sensor. The presence of significant noise in the signal can be attributed to several factors. First, the periodical spike in the signal might be due to a glitch in Digital to Analog converter (D/A) [10] embedded in the relatively inexpensive fiber optical sensor. Secondly, the high rotational speed of the micro-milling machine spindle also amplifies noise in the sensor's output signal [11]. Therefore it was decided to run the tool setting process when the tool was at rest. 
Figure 3 shows an example of the white noise at full light intensity with nothing between the receiver and the transmitter. The noise was primarily manifested as periodical spikes. This noise can be detrimental to the tool setting process by affecting the robustness of the search algorithm. The frequency and duration of the spikes were found to be consistent over time. The time between each instance of spike is approximately 0.2 seconds $(5 \mathrm{~Hz})$ and each instance has a duration of about 0.04 seconds. The full light intensity is converted to be around $1.62 \mathrm{~V}$ and the magnitude of the spike is about $0.02 \mathrm{~V}$ in magnitude. In order to achieve robust edge detection, the spike in the signal should be filtered before a threshold based algorithm can be applied. To this end, we organized the original data into consecutive samples. Each sample consists of the data collected within a duration of $0.04 \mathrm{~s}$. At a sampling frequency of $500 \mathrm{~Hz}$, each sample consists of 20 consecutive measurements $(0.04 \mathrm{~s} * 500 \mathrm{~Hz}=20)$. The spike in the original signal diminished down to be below $0.004 \mathrm{~V}$ in magnitude in the sample mean as shown in Figure 3 . The sample mean can be considered as a low passing filter. It is evident that if we use the sample mean for the tool tip detection, the algorithm will be much more robust. To further enhance the robustness of the tool tip detection, a sample range based outlier discriminator was used to remove the samples containing spikes.

\section{Figure 3: White noise present in sensor signal}

\subsection{SENSOR SENSITIVITY OF OPTICAL OCCLUSION}

A micro-endmill with a diameter of $100 \mu \mathrm{m}$ was used to test the sensitivity of the optical occlusion. The same initial test was performed to ensure that the tool axis and the center of the light beam fall into the same XZ plane and the tool cuts halfway into the light beam, similar to the case shown in Figure 2. As the tool starts to back off along the $\mathrm{Z}$ axis, the occlusion of the optical beam gradually decreases and the light intensity increases, causing the output voltage to increases. Both the encoder reading of the $\mathrm{Z}$ axis and the senor output voltage were collected using the motion controller and plotted in Figure 4. It can be clearly seen that the there is a significant output voltage of around $1.08 \mathrm{~V}$ even when the tool was fully immerged in the way of the light beam, suggesting that the diameter of the light beam is larger than the diameter of the tool used. The overall voltage change from full occlusion to no blocking (full light intensity) is about $0.54 \mathrm{~V}$. According to the sensor specification, the minimum detectable object is 5 microns in 
diameter. For a 100 micron diameter tool, it is expected that a depth of sub-micron immersion into the beam should be readily detectable.

\section{Figure 4: Sensitivity of optical occlusion from a micro-endmill of $100 \mu \mathrm{m}$ in diameter}

\subsection{TOOL TIP DETECTION PROCEDURE}

The tool tip detection by the fiber optical sensor is the most critical stage in tool setting. The procedure is depicted in Figure 5. Before the process starts, some preparation is needed. This includes collecting full light intensity data at the sampling frequency of $500 \mathrm{~Hz}$ in real time for a period of one second and computing the grand mean of the output voltage $\mathrm{V}_{0}$, and the maximum sample range $\mathrm{R}_{\max }$, where the sample size was set to be 20 (corresponding to duration of $0.04 \mathrm{~s})$. The sample size was determined by the duration of the spike in the white noise. The $\mathrm{R}_{\max }$ will later be used to reject the samples containing noisy spikes. The XY axes also rapidly move to the location where the tool center and the light beam are aligned properly in the same XZ plane as shown in Figure 5.

\section{Figure 5: Flow chart of the edge search/detection algorithm}

Once the preparation stage is done, the quick light beam search starts (Step 1 in Figure 5). The tool approaches the light beam at a fast rate in a few micro-steps. The micro-step size is set at $64 \mu \mathrm{m}$. At the end of each micro-step, five light intensity samples (with same sample size of 20) will be collected by the motion controller. The sample range will be computed and compared with the $\mathrm{R}_{\max }$. If it exceeds $50 \%$ of $\mathrm{R}_{\max }$, the sample is discarded. This can be considered as a range-based outlier discriminator to clean the original data. The grand mean of the sample mean of the valid samples will then be computed and compared to the threshold of $\mathrm{V}_{0^{-}}-0.04$, which corresponds to about $2.5 \%$ drop of full light intensity. If the grand mean is lower than the threshold value, the tool will stop. At this time, the tool should already intercept the beam. Then the tool retreats at a reduced step size of $16 \mu \mathrm{m}$ until the light intensity recovers to above $\mathrm{V}_{0}-0.008$, which is about $99.5 \%$ of full light intensity. Now the tool should be within a few microns from the edge of the light beam. Finally, the high resolution honing of the edge detection starts, with the tool first moving into the beam 
for a fixed distance of $20 \mu \mathrm{m}$ to compensate for the possible overshoot from the previous step and then retracing back with a much finer step size of $0.5 \mu \mathrm{m}$. The light intensity threshold will stay the same as previous step, i.e., until the light intensity recovers back to at least $99.5 \%$ of the full intensity. These reciprocal motions allow the machine to home very precisely on the edge of the light beam with high efficiency and repeatability. The encoder reading of the $\mathrm{Z}$ axis is recorded as z3. The tool length offset was then computed as z3- $d$, where $d$ is the fixed displacement between the light beam and the reference surface on the workpiece. Finally the tool length offset was registered in the motion controller. The entire process takes about 10 s to complete.

The algorithm was implemented in the motion controller as a special program. The program can be called using a designated preparatory G-code (G65) in a CNC program. Figure 6 shows a graphical view of the tool tip detection algorithm in action. The green line shows the history of the light intensity change over the course of the tool tip search, while the blue line presents the $\mathrm{Z}$ axis movement in the process. As the tool travels in toward the light beam, the $\mathrm{Z}$ axis location line has an apparent downward slope, i.e, the tool travel in the negative direction (towards the light beam). When the tool crosses the light beam and the light intensity decreases, the tool begins to retract. In this step, the overall travel range is very small, the change in the $\mathrm{Z}$ axis location is so subtle that the graph had to be zoomed in (in Error! Reference source not found.) in order to be observed clearly. Starting from around the $4 \mathrm{~s}$ mark, the tool started to retract with a step size of $16 \mu \mathrm{m}$ shown as a zigzag blue line. This is the second step in the algorithm: quick retrace to edge (Refer to Figure 5). The green line showed the steadily increased light intensity as the tool retracted out of the light beam. As soon as the light intensity reached the threshold, the tool was moved back into the light beam again and then the step three in the algorithm (high resolution honing) started. This occurred at around the 6s mark, we saw the blue line gradually moved up and eventually flattened out and finished the edge detection process. The graph clearly shows how the high resolution edge detection procedure finds the exact edge of the light beam with in-and-out motion.

Figure 6: Light intensity change in the tool tip detection process 


\section{Figure 7: Zoomed in View of the tool tip detection process}

\section{EXPERIMENTATION}

\subsection{REPEATABILITY OF TOOL TIP DETECTION}

Two micro-endmills with diameters of $100 \mu \mathrm{m}$ and $500 \mu \mathrm{m}$ were used for the experiments. Five trials of tool tip detection were conducted for each tool from arbitrary starting points. The data summarized in Table 1 are the final $\mathrm{Z}$ locations when the tool tip detection is completed. It is observed that the repeatability of the tool with the larger diameter of $500 \mu \mathrm{m}$ is significantly better than the one with the smaller diameter of $100 \mu \mathrm{m}$. The pooled standard deviation of tool location was $0.301 \mu \mathrm{m}$, which gave a $2 \sigma$ repeatability of $0.602 \mu \mathrm{m}$ across different tools. The repeatability is comparable to the commercially available tool setters such as Renishaw NC4 non-contact tool setter which claimed to have a $2 \sigma$ repeatability of $0.1 \mu \mathrm{m}$ [6]. More importantly, the high repeatability was achieved with only a fraction of the cost of the commercially available units.

Table 1: Repeatability of tool tip detection algorithm

\begin{tabular}{|c|c|c|c|c|c|c|c|}
\hline & \multicolumn{5}{|c|}{$\mathrm{Z}$ value at the end the tool tip detection $(\mathrm{mm})$} & \multirow{2}{*}{$\begin{array}{c}\begin{array}{c}\text { Standard } \\
\text { Deviation }(\mathrm{mm})\end{array} \\
8.9442 \mathrm{E}-05\end{array}$} & \multirow{2}{*}{$\begin{array}{r}\begin{array}{c}\text { Repeatability } \\
(\mu \mathrm{m})\end{array} \\
0.179\end{array}$} \\
\hline $\begin{array}{l}\text { Tool \#1 } \\
(500 \mu \mathrm{m})\end{array}$ & -27.8371 & & -27.8373 & -27.8372 & -27.8371 & & \\
\hline $\begin{array}{l}\text { Tool \#2 } \\
(100 \mu \mathrm{m}) \\
\end{array}$ & -28.4552 & -28.4553 & -28.4543 & -28.4552 & -28.4552 & 4.1593E-04 & 0.832 \\
\hline & & & & \multicolumn{2}{|c|}{$2 \sigma$ Repeatability } & tion $\sigma$ & $\begin{array}{l}0.301 \\
0.602\end{array}$ \\
\hline
\end{tabular}

\subsection{TOOL SETTING ACCURACY IN REAL MICRO-MACHINING SETTING}

In order to test the accuracy of the tool setter in an actual micro-machining process, two shallow holes of identical programmed depth of $10 \mu \mathrm{m}$ were created on a flat reference surface of the workpiece with a $500 \mu \mathrm{m}$ micro-endmill in two separate tool setups. This design was derived from the general two step procedure for setting tool length offset for 
any CNC milling machine. The first step was to establish a standard length. This standard length is the length of a reference tool, which is usually the first tool to be used. The reference tool was mounted on the machine and the $\mathrm{Z}$ axis was jogged to a fixed location (in our case is the edge of the light beam from the non-contact tool setter) and the $\mathrm{Z}$ position was recorded as the $\mathrm{Z}$ reference. The $\mathrm{CNC}$ controller registered this $\mathrm{Z}$ reference. The tool length offset for the reference tool was set to be Zero. The second step was to setup the tool length offset for all the other tools by going through the same touch off procedure and the controller compares the $\mathrm{Z}$ axis positions with the previously stored $\mathrm{Z}$ reference, the difference of which was stored as the tool length offset for that tool. Since there is no tool magazine in the micro-milling machine to hold multiple tools, each time a tool is replaced, we have to consider it as a new tool, and the tool length offset needs to be set using the same touch off procedure because the extension from the spindle can be different each time a tool is re-chucked.

When the $500 \mu \mathrm{m}$ micro-endmill was first mounted to the spindle, the tool was treated as a reference tool, a reference zero is established after the tool setting procedure and a hole of $10 \mu \mathrm{m}$ in depth was machined. The tool was then removed from the spindle, then rechucked. This time the tool was treated as a new tool and its length offset was set to compensate the difference in the extension length of the two setups. The same machining program was then run to machine another hole of $10 \mu \mathrm{m}$ in depth. If there was an error in the tool setting procedure, the machined holes would have ended up with different depths. The difference can be considered as the upper bound of the tool setting error. The two holes were examined with on-the-machine scanning microscope [12]. Data collected from the surface scan indicated roughly a $2 \mu \mathrm{m}$ difference in the depth as shown in Figure 6 . The result proves that the tool setting accuracy is within $2 \mu \mathrm{m}$, which is satisfactory for most of micro-machining applications.

\section{Figure 8: Tool setting accuracy (difference in depths of the two holes with equally set depths)}

\section{CONCLUSIONS}

The following conclusions can be made from the research:

1) A fiber optic sensor Keyence FS-V30M was selected to build the non-contact tool setter for the micro-milling machine. The sensor emits a light beam from its light-emitting element. On the receiving side, the sensor 
measures the change in the light intensity caused by the target (micro-tool) crossing the optical axis. The smallest detectable object is $5 \mu \mathrm{m}$, which is sufficient for micro-tool detection $(50 \mu \mathrm{m} \sim 500 \mu \mathrm{m})$.

2) A novel edge detection and search algorithm was developed to accurately locate the edge of the emitted light beam in the presence of significant noise. The influence of the noise was minimized through averaging. Furthermore, a sample range based outlier discriminator was used to take the noise data out.

3) The algorithm was implemented in the CNC machine controller for tool setting. The system achieved $0.6 \mu \mathrm{m}$ repeatability for across different tools and a $2 \mu \mathrm{m}$ accuracy in the actual micro-machining setup. The tool setting takes about 10 seconds, which is $80 \%$ $90 \%$ reduction from manual tool setting.

4) As future work to further improve the repeatability and the accuracy, a sensor with a cleaner signal and a better sensitivity to the occlusion should be sought to replace the one used in this research. Another approach to improve the performance of the system is to apply more advanced band pass digital filter to clean up the noise in the signal, instead of simply using moving average values.

\section{ACKNOWLEDGEMENTS}

This research is partially supported by the Lamar University Research Enhancement Grants to Dr. Xinyu Liu and National Science Foundation Grant \#1140457 to Dr. Weihang Zhu.

\section{References}

1. Adams, D.: Microgrooving and microthreading tools for fabricating curvilinear features. Precision Engineering 24, 347-356 (2000)

2. Vogler, M.: Development of meso-scale machine tool (mMT) systems". Transactions of the North American Manufacturing Research Institution of SME(NAMRI) 30, 653-661 (2002)

3. Özel, T. .: Investigations on Mechanics Based Process Planning of Micro-End Milling in Machining Mold Cavities. Materials and Manufacturing Processes 24(12), 1274-1281 (2009)

4. Kornel F. Ehmann, D.: International Assessment of Research and Development. World Technology Evaluation Center (WTEC), Inc., Baltimore (2005)

5. Tormach Touch Probes and Tool Setter. In: Tormach. Available at: http://www.tormach.com/product tts_electronics.html

6. Available at: http://www.blum-novotest.de/measuring-components/products/laser-tool-setting/lasercontrol-ec.html

7. Available at: http://www.renishaw.com/en/nc4-non-contact-laser-tool-setter--6099

8. K. Popov, S.: New tool-workpiece setting up technology for micro-milling. International Journal of Advanced Mnaufacturing Technology 47, 21-27 (2010) 
9. Gandarias E, D.: New mthods for tool failure detection in micromilling. Proceedings of Institute of Mechanical Engineers, Part B Journal of Engineering Manufacture 220(2), 137-144 (2006)

10. Razavi, B.: Principles of Data Conversion System Design. IEEE Press (1995)

11. Malekian, M.: "Tool wear monitoring of micro-milling operations. Journal of Materials Processing Technology, 4903-4914 (2009)

12. Liu, X.: In-situ Metrology System for Micro-Milling Machine. Journal of Manufacturing Systems 31(1), 15-21 (2012) 
Table 1: Repeatability of tool tip detection algorithm

\begin{tabular}{|c|c|c|c|c|c|c|c|}
\hline & \multicolumn{5}{|c|}{$\mathrm{Z}$ value at the end the tool tip detection $(\mathrm{mm})$} & \multirow{2}{*}{$\begin{array}{c}\begin{array}{c}\text { Standard } \\
\text { Deviation }(\mathrm{mm})\end{array} \\
8.9442 \mathrm{E}-05\end{array}$} & \multirow{2}{*}{$\begin{array}{r}\begin{array}{c}\text { Repeatability } \\
(\mu \mathrm{m})\end{array} \\
0.179\end{array}$} \\
\hline $\begin{array}{l}\text { Tool \#1 } \\
(500 \mu \mathrm{m})\end{array}$ & -27.8371 & -27.8371 & -27.8373 & -27.8372 & -27.8371 & & \\
\hline $\begin{array}{l}\text { Tool \#2 } \\
(100 \mu \mathrm{m})\end{array}$ & -28.4552 & -28.4553 & -28.4543 & -28.4552 & -28.4552 & 4.1593E-04 & 0.832 \\
\hline & & & & \multicolumn{3}{|c|}{ Pooled Standard Deviation $\sigma$} & 0.301 \\
\hline & & & & \multicolumn{3}{|c|}{$2 \sigma$ Repeatability } & 0.602 \\
\hline
\end{tabular}


Through holes to hold Transmitter and receiver

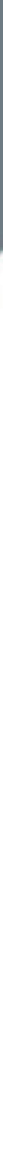


Tool intercept light beam

Mounting Bracket

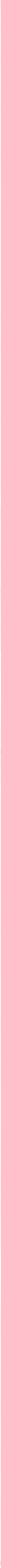


Original Samples
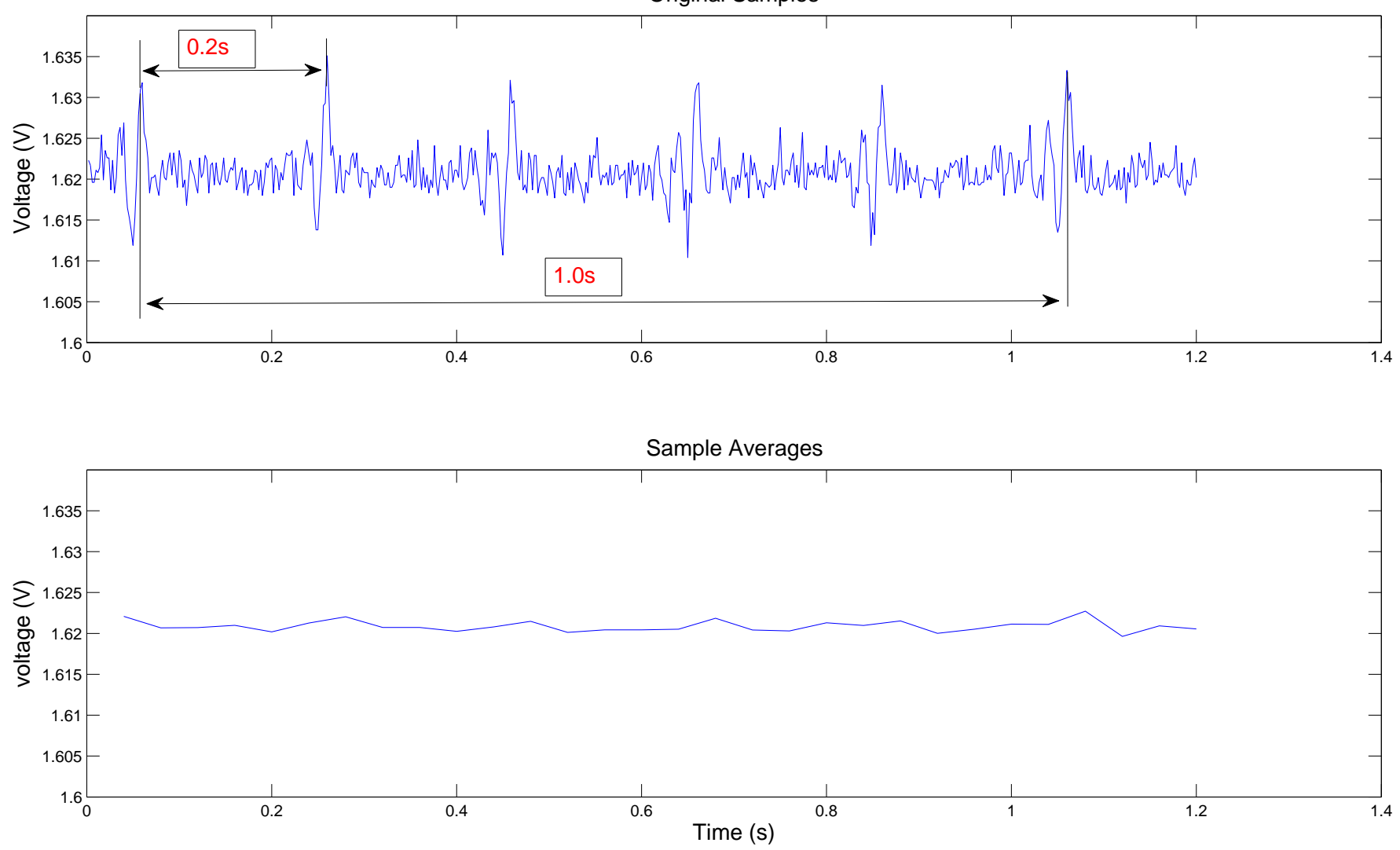


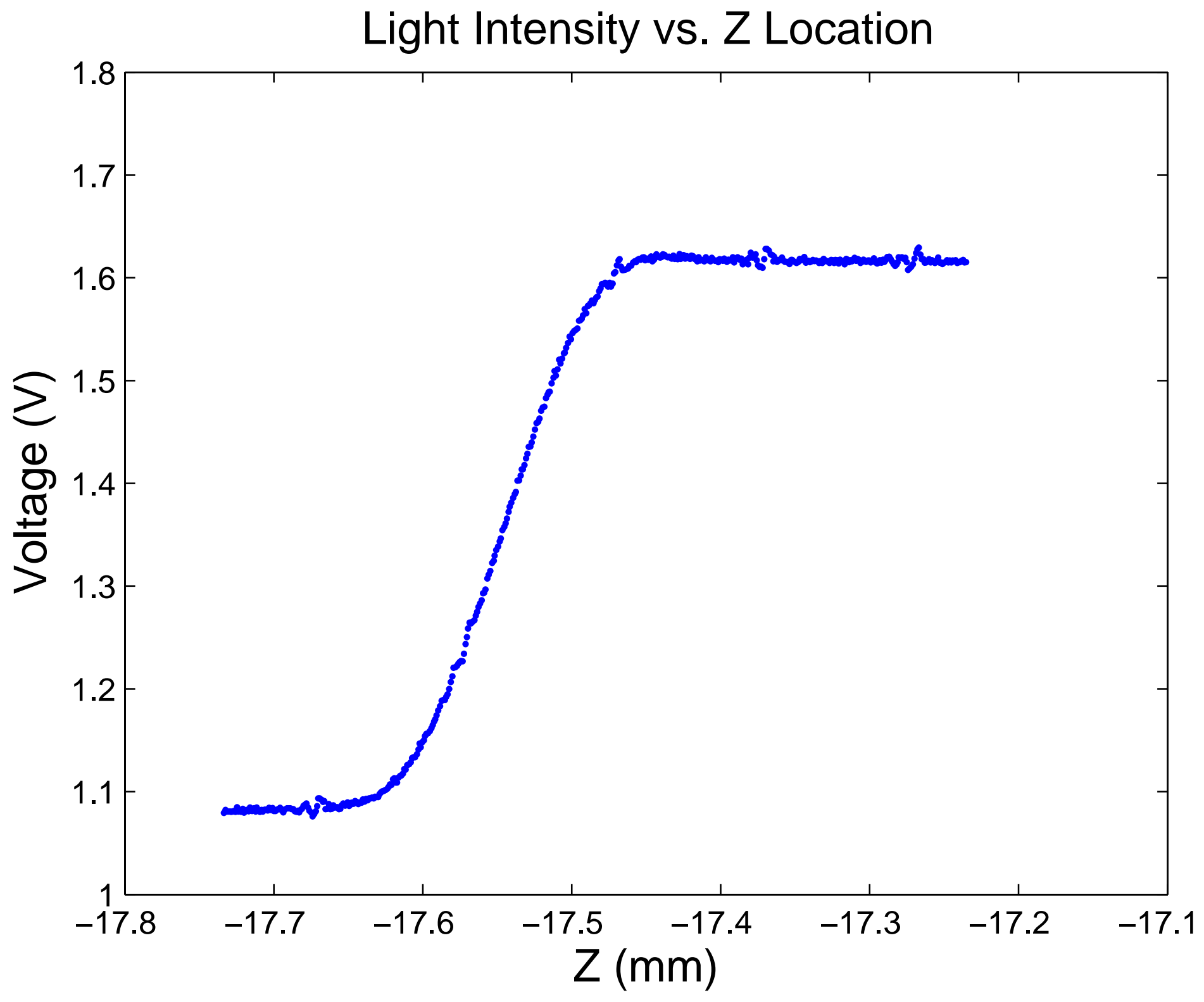



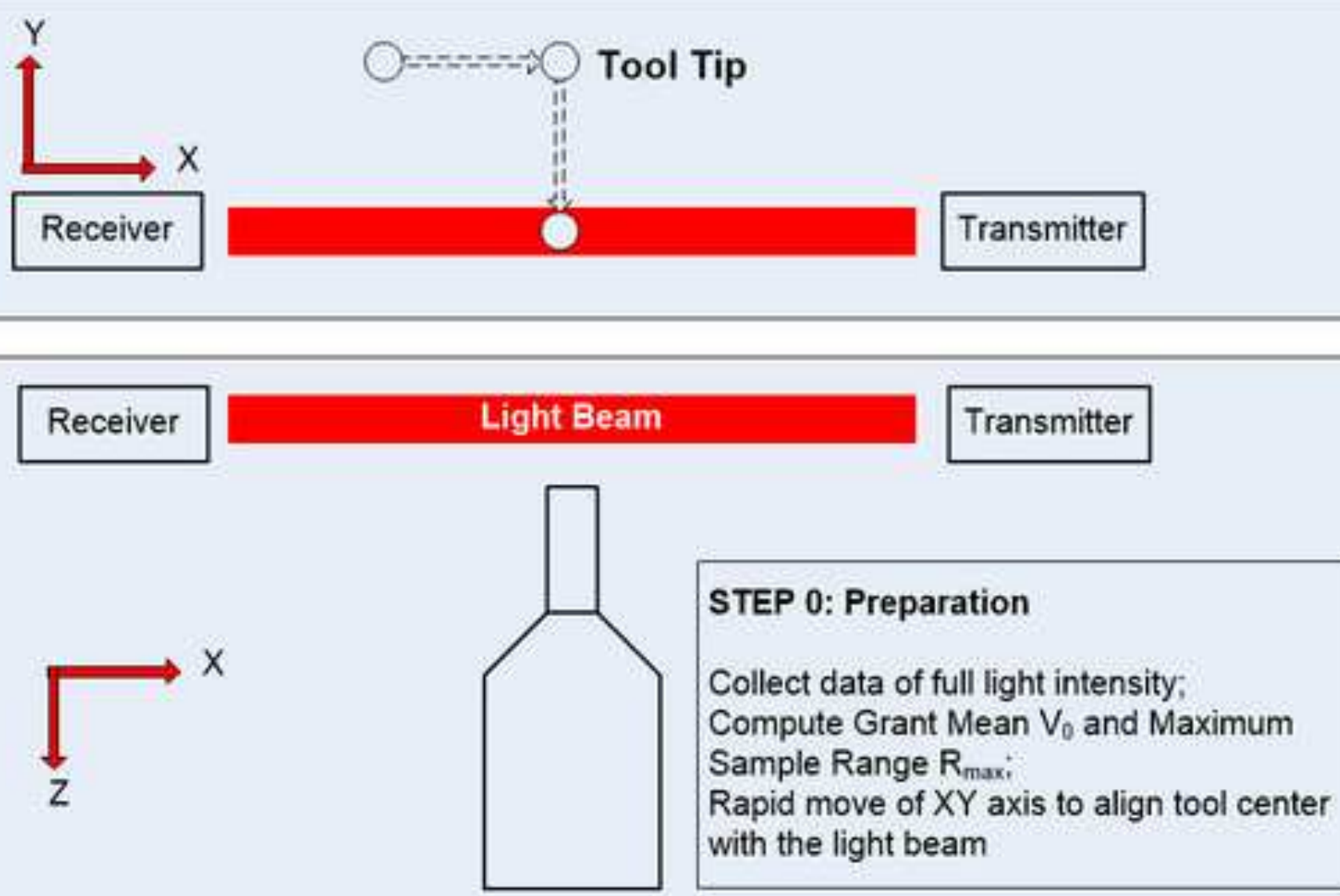
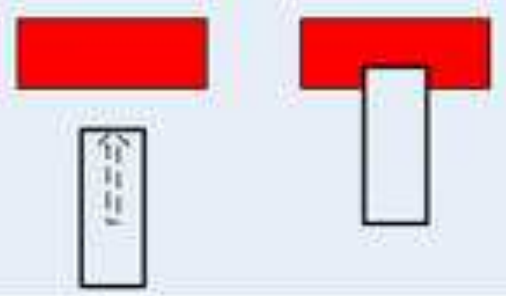

STEP 1: Quick Light Beam Search

Step size: 64 um Threshold: $V_{0}=0.04(\sim 2.5 \%$ drop of full intensity)
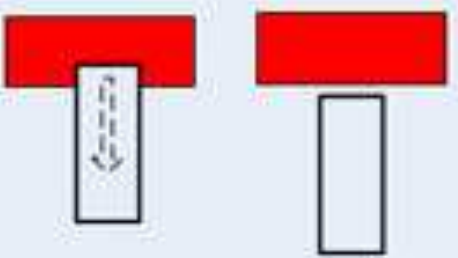

STEP 2: Quick Retrace to Edge

Step size: 16 um

Threshold: $V_{0}-0.008(\sim 0.5 \%$ drop of full intensity) Maximum overshoot: 16 um

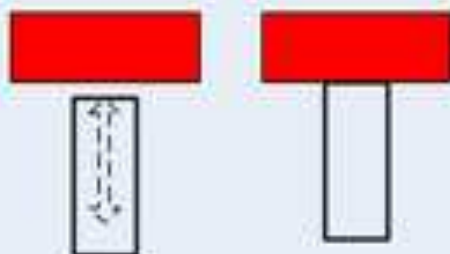

STEP 3: High Resolution Honing of Edge Location

Step size: 0.5 um

Threshold: $V_{0}=0.008(\sim 0.5 \%$ drop of full intensity) 


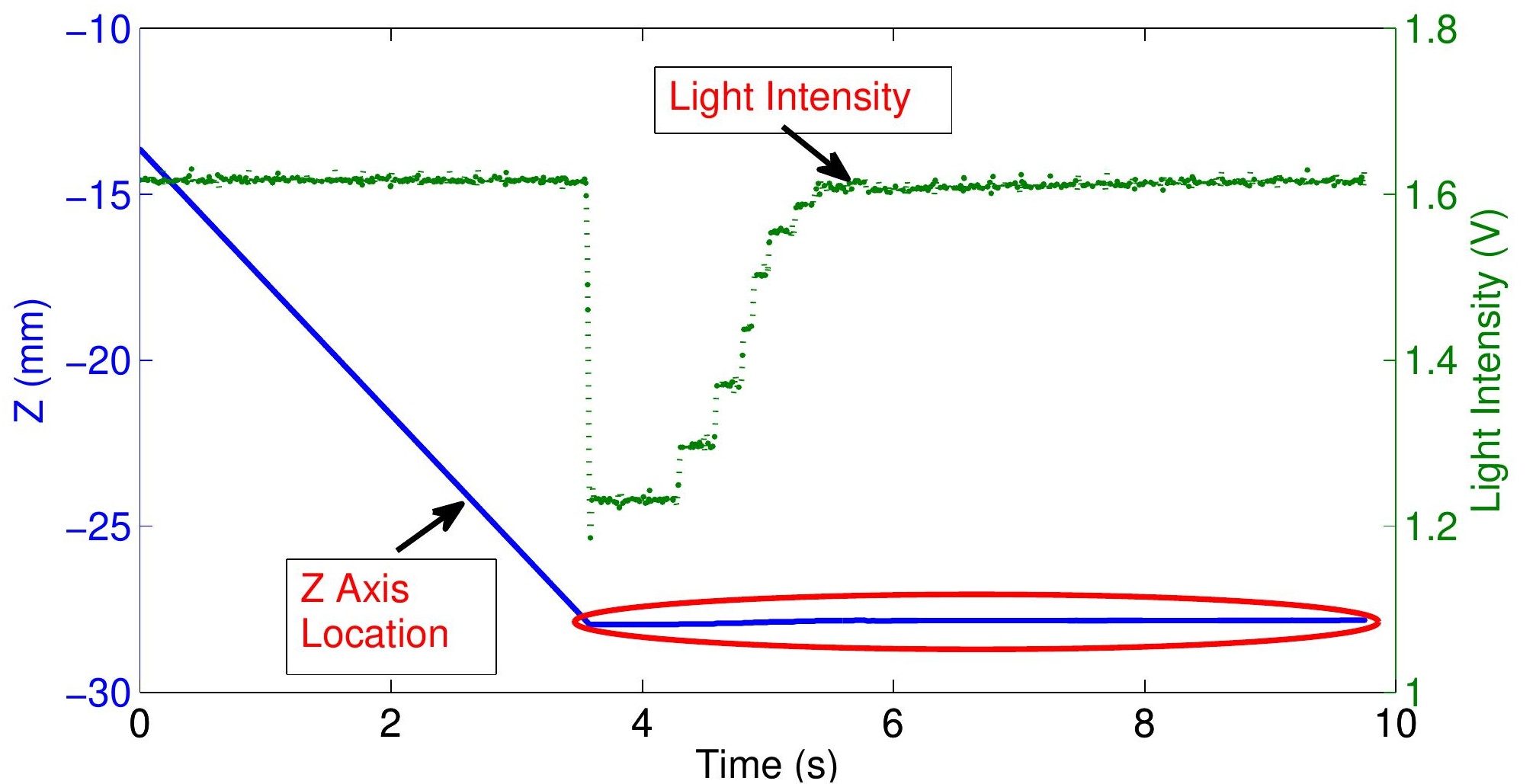




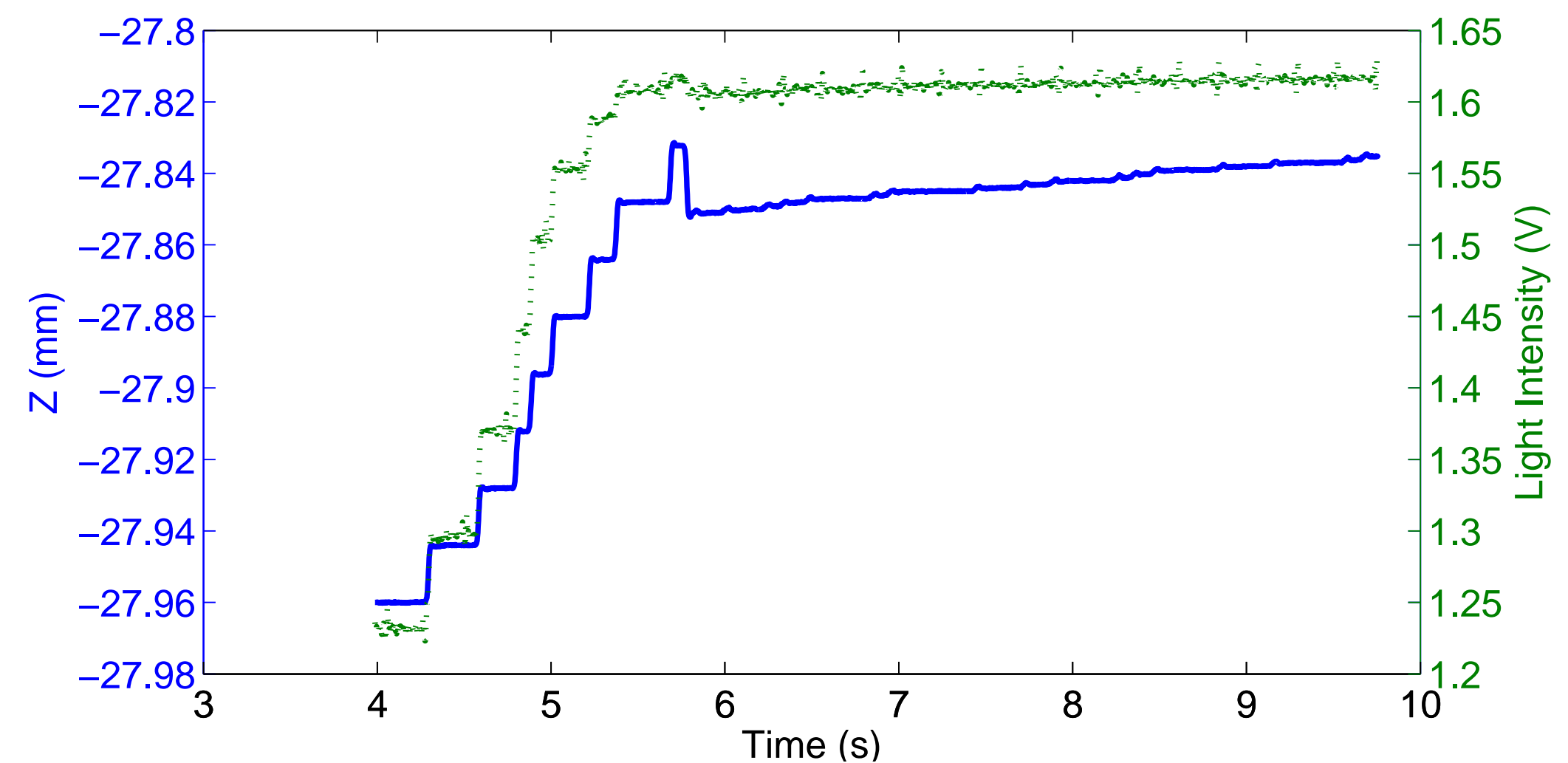


X Profile

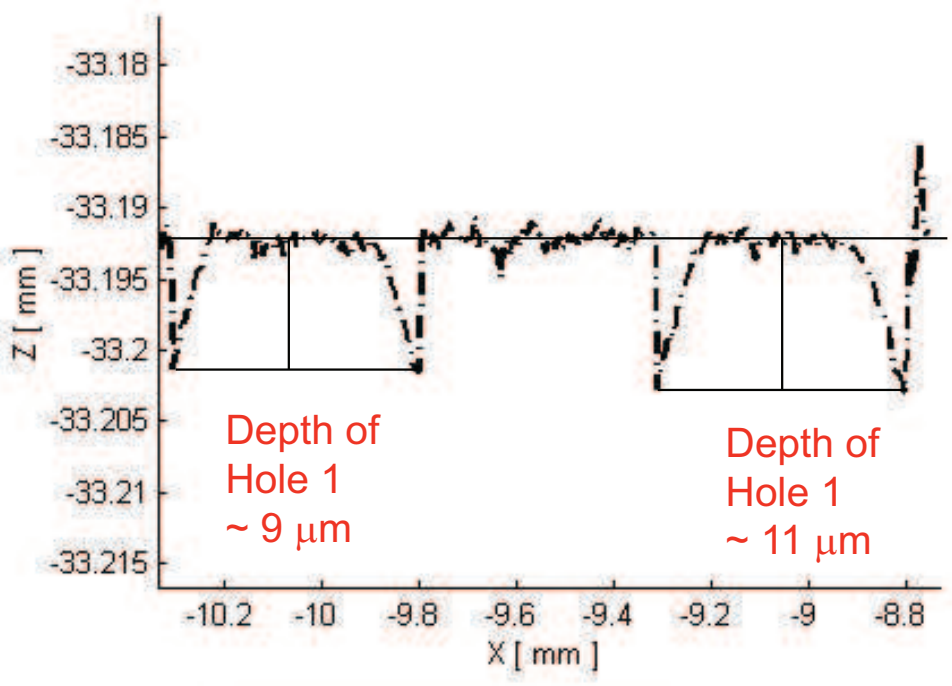

Y Profile
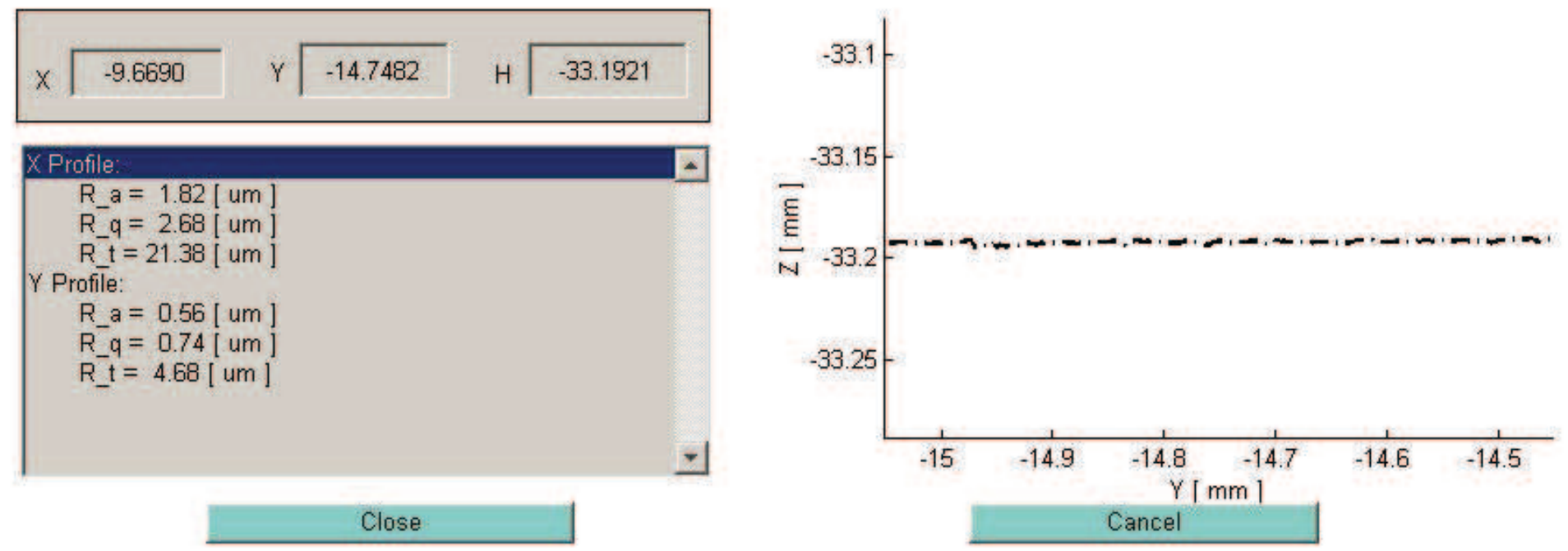